\title{
Stealthy Monitoring and Control of Vehicle Safety System
}

\begin{abstract}
In recent times, traffic rules are more often violated by the drivers. And, also driving at high speed needs to be controlled. So, stealthy monitoring and control of the vehicle is required. Sometimes it is not possible to see the boards and traffic symbols kept alongside of the road. The main objective of this paper is to design and develop an efficient system that can effectively detect speed violations on the road using $R F$ technology. The proposed system gives an alert to the driver through LCD and voice boards. In the proposed system, if over speeding vehicles don't get controlled manually, then the system turns $\mathrm{ON}$ and will get controlled automatically and detect any vehicle opposite to, utilizing the vehicle on-board unit. The challenges to overcome include GSM-based Accident/Panic alert using ARDUINO mega.
\end{abstract}

Keywords: RFID module, accelerometer sensor, ultrasonic sensor, GSM module, voice playback board, alcohol sensor.

\section{INTRODUCTION}

$\mathrm{R}$ oad accidents are the major cause for unnatural death and causality over the world from the past decades. As per the survey held by World Health Organization (WHO), around 1.3 million people are losing their lives due to road accidents every year and more than 50 million people get injured. The numeral count of road accidents are increasing due to over speeding, negligent driving, drink and drive, poor vicinity of roads etc. Among these reasons, over speeding is the major cause for the accident. The problem of over speeding becomes more dangerous in the rainy, winter and spring season. Also the roads which has full of turns are more prone to accidents. In order to reduce the count of accidents, the respective department of government has been deploying necessary steps like sign boards, speed humps etc., these steps need an individual riders attention which is not taking place effectively. So that it is necessary to design the smart system to alert the driver about the accident zone and to control the speed of the vehicle. Using the advancement of technology a new system is designed to prevent the road accidents. RF ID technology is used to identify the school and college zone and control the speed of vehicle. That alerts the driver about the zone to control the speed of the vehicle. The location based values like latitude and longitude of mobile devices are keeping on updated to the server. When the devices enter the geo-fenced area, the notifications are sent to the controlling part of the vehicle from the server.

Revised Manuscript Received on April 02, 2020.

* Correspondence Author

T. Dharanika*, Asst.Prof (EEE Dept) at Sri Krishna College Of Technology, Coimbatore-641042 Email: dharanika.t@skct.edu.in

S.Sridharshini, Student, (EEE Dept) at Sri Krishna College Of Technology,Coimbatore-641042Email:sridharshinisasikumar99@gmail.co $\mathrm{m}$

V.Shanmugapriya, Student, (EEE Dept) at Sri Krishna College Of Technology, Coimbatore-641042 Email: shanmugapriya6970@gmail.com

K.Ramya, Student, (EEE Dept) at Sri Krishna College Of Technology, Coimbatore-641042 Email: acwramya@gmail.com

K.Sathya Deepa, Student, (EEE Dept) at Sri Krishna College Of Technology, Coimbatore-641042Email: sathyadeepa1327@gmail.com

(C) The Authors. Published by Blue Eyes Intelligence Engineering and Sciences Publication (BEIESP). This is an open access article under the CC BY-NC-ND license (http://creativecommons.org/licenses/by-nc-nd/4.0/)
The Controlling part in the system activates the necessary action to control the speed of the vehicle based on the notifications

Number of road accidents per lakh population

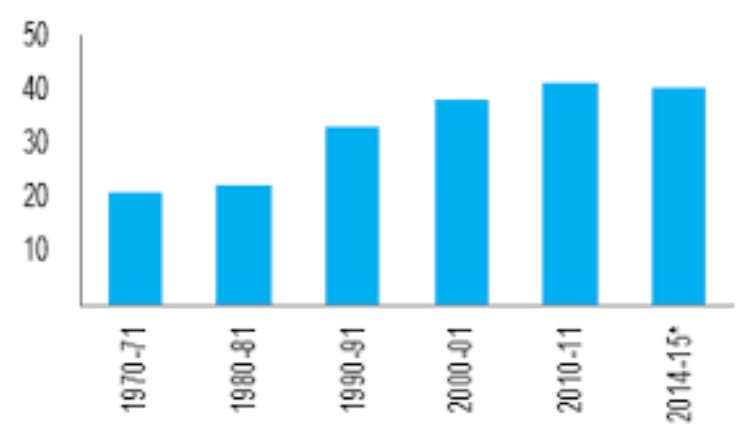

FIG.1

\section{OBJECTIVE}

Everyone must be safe during travelling. Vehicle safety has become an objective to save people from injuries in the event of road accidents. Safety minimizes the loss of life and property. We have many automobile safety equipment's like ABS, airbags etc. But the main objective is to prevent these cases before it can occur. This can be achieved using a multi-sensor network which is integrated to each other and transfer the required information through a microcontroller.

\section{WORKING}

The proposed system is based on three units. It has four implementation parts: First, we monitor the alcohol level using an Arduino controller. Second, we control the vehicle speed in school zone, college zone and traffic areas. Third detect any accident by using accelerometer sensor and GSM. Fourth detect object using ultrasonic senor. Here ARDUINO mega micro controller is the main heart of the system followed by alcohol sensor, GSM, LCD, RF ID, DC motor, accelerometer sensor, ultrasonic sensor and voice module. The RFID is placed in the places like school, colleges, Hospitals or any dangerous point on a highway, whenever the vehicle enters in the speed control zone RFID Reader crosses the tag, so it sense that the vehicle has entered the speed control zone, and controls the speed according to the zone . Alcohol sensor is used to detect the driver condition while driving. If the driver drunk alcohol, vehicle doesn't start. By the help of alcohol sensor we monitor the alcohol level in LCD display. Ultrasonic sensor is used to detect object opposite to us. It produces the buzzer sound when object came opposite to us. Above information are stored in voice board. Any faults occur during driving means, it starts act respective work like "alcohol detected", "object detected", "school zone".

Published By:

Blue Eyes Intelligence Engineering DOI: 10.35940/ijeat.D6677.049420

Journal Website: www.ijeat.org

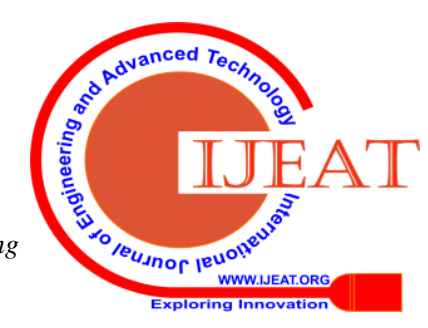


In case any accident means, like car roll over or unconditional driving, GSM send the message to particular member. All the results are continuously monitored in LCD display for our reference.

\section{BLOCK DIAGRAM}

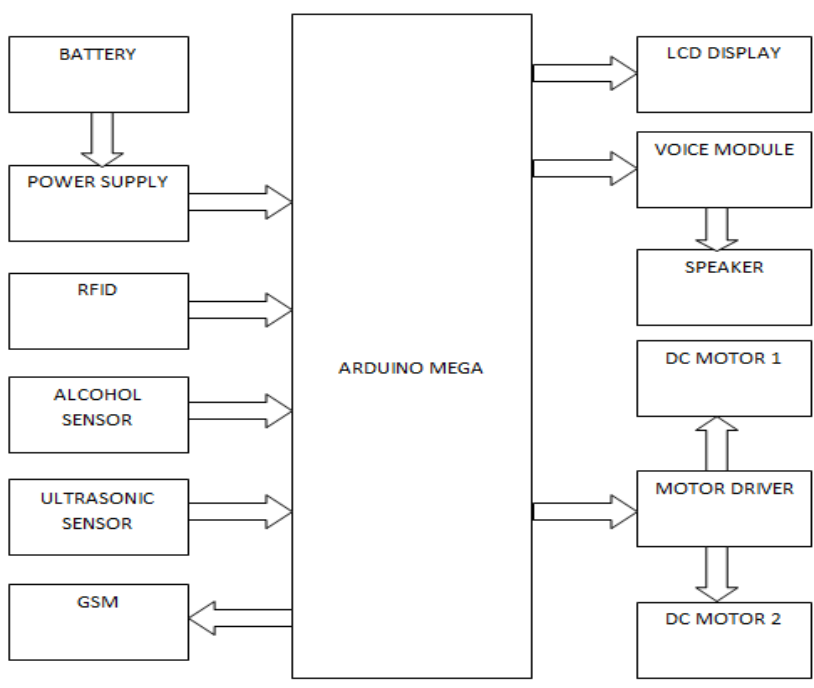

FIG.2

\section{HARDWARE DESCRIPTION}

\section{A. Description Of Arduino Mega}

The Arduino Mega 2560 is used for this application since it has 54 digital input/output pins in which 14 can be used as PWM outputs. In addition to that, it has 16 analog ports, 4 UARTs, a $16 \mathrm{MHz}$ crystal oscillator etc.

The power pins are as follows:

1. V input-

Arduino requires a $5 \mathrm{~V}$ input for its working. So the input $5 \mathrm{~V}$ is given from the power supply circuit.

2. 3 V3-

The on-board regulator can generate up to $3.3 \mathrm{v}$ which draws $50 \mathrm{~mA}$ maximum current.

3. GND-

Ground pins.

\section{B. Power Supply Circuit}

The step down transformer can reduce the voltage to the required levels. In India, $1 \varnothing$ supply is given at $230 \mathrm{~V}$. The output from the transformer is a pulsating sinusoidal AC voltage, using a rectifier it is converted to pulsating DC. Then the output is given to a filter and smoothening circuit which reduces the ripples present in the supply, and allows the DC components only.
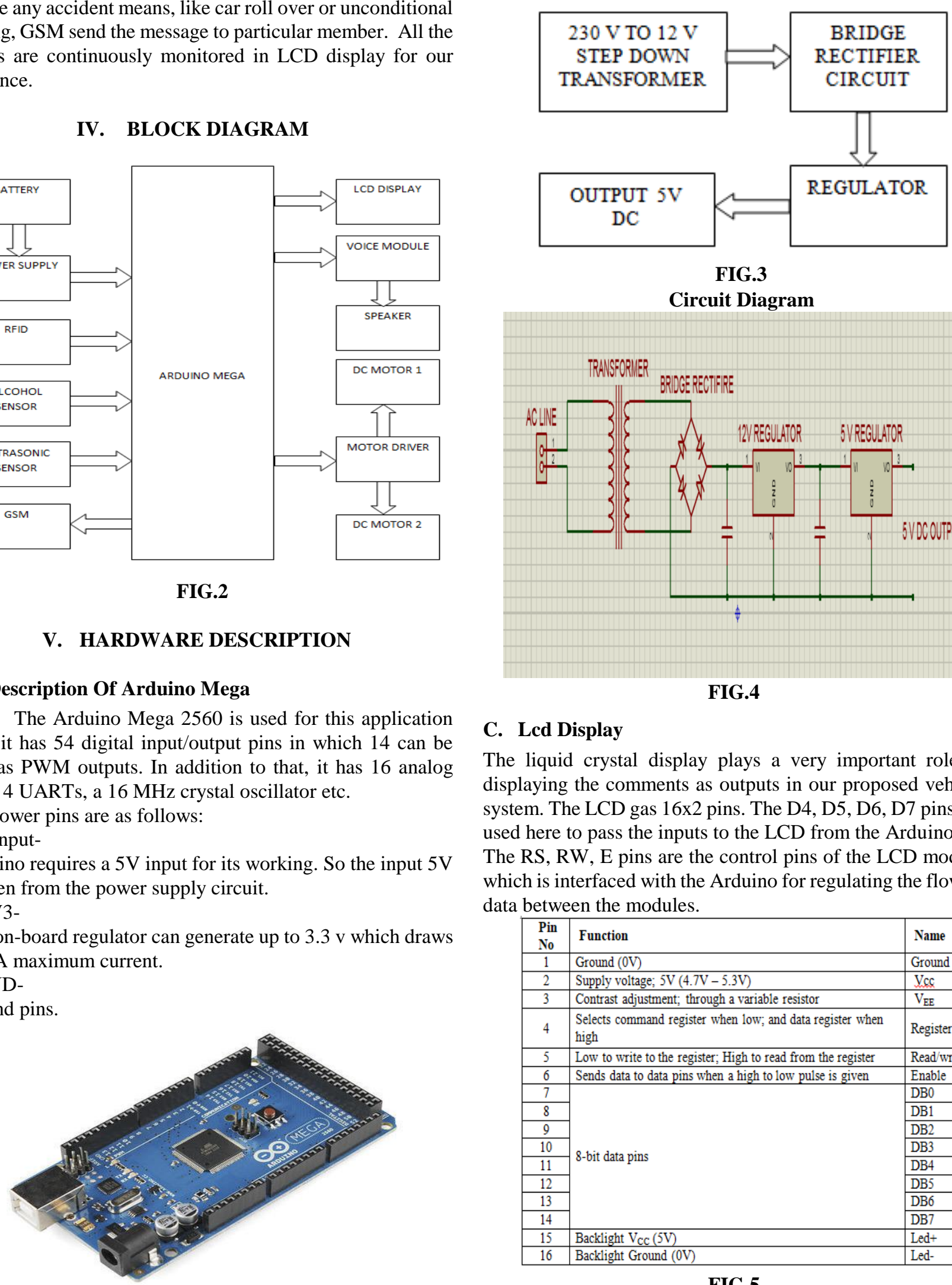

FIG.3

Circuit Diagram

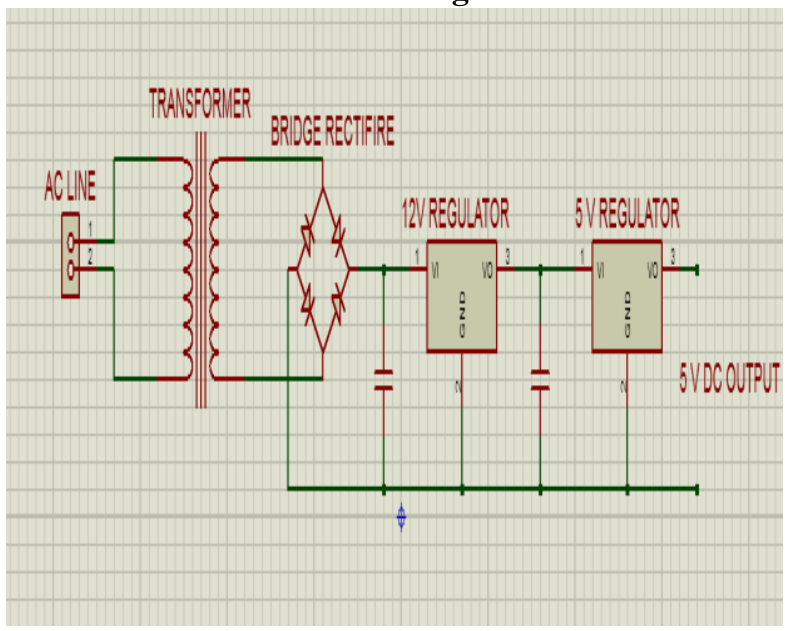

FIG.4

\section{Lcd Display}

The liquid crystal display plays a very important role in displaying the comments as outputs in our proposed vehicle system. The LCD gas 16x2 pins. The D4, D5, D6, D7 pins are used here to pass the inputs to the LCD from the Arduino.

The RS, RW, E pins are the control pins of the LCD module which is interfaced with the Arduino for regulating the flow of data between the modules.

\begin{tabular}{|c|c|c|}
\hline $\begin{array}{l}\text { Pin } \\
\text { No }\end{array}$ & Function & Name \\
\hline 1 & Ground $(0 \mathrm{~V})$ & Ground \\
\hline 2 & Supply voltage; $5 \mathrm{~V}(4.7 \mathrm{~V}-5.3 \mathrm{~V})$ & Vsc \\
\hline 3 & Contrast adjustment; through a variable resistor & $\mathrm{V}_{\mathrm{EE}}$ \\
\hline 4 & $\begin{array}{l}\text { Selects command register when low; and data register when } \\
\text { high }\end{array}$ & Register Select \\
\hline 5 & Low to write to the register; High to read from the register & Read/write \\
\hline 6 & Sends data to data pins when a high to low pulse is given & Enable \\
\hline 7 & \multirow{8}{*}{ 8-bit data pins } & DB0 \\
\hline 8 & & DB1 \\
\hline 9 & & DB2 \\
\hline 10 & & DB3 \\
\hline 11 & & DB4 \\
\hline 12 & & DB5 \\
\hline 13 & & DB6 \\
\hline 14 & & DB7 \\
\hline 15 & Backlight $\mathrm{V}_{\mathrm{CC}}(5 \mathrm{~V})$ & Led + \\
\hline 16 & Backlight Ground (0V) & Led- \\
\hline
\end{tabular}

FIG.5

\section{Alcohol Sensor}

MQ-3 gas sensor is made up of aluminium oxide, tin dioxide, electrodes and heater. The sensor senses the alcohol content in the breathe, and does not turn on if the limit exceeds the given value.

\section{Published By:}

Blue Eyes Intelligence Engineering

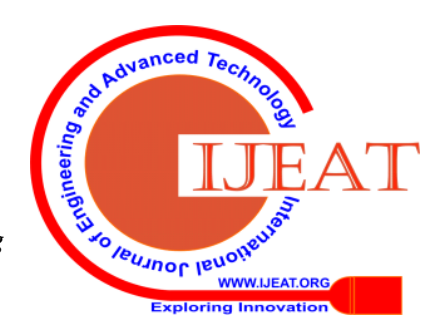


There are 6 pins, out of which 4 are used to send and receive signals. An MQ-3 sensitive component consists of 2 parts. The sensor output is connected to the analog input pin of the Arduino mega at any one of the analog pins.

\section{E. Rfid Module}

Basically RFID is a technology we use to identify objects electronically. The RFID Reader module works at $125 \mathrm{KHz}$. It is an efficient method for RFID application. The reader module contains an on-chip antenna and is powered with a $5 \mathrm{~V}$ power supply. Two main components are: the tag and it's reader. Tags are kept between $4 \mathrm{~cm}$ distance from the reader. The reader works like a scanner, it uses electromagnetic waves. The reader is connected to the Arduino board and receives the signals in the digital pins.

\section{F. Voice Playback Module}

The voice playback module gives voice signals to the driver/passengers so that even if they fail to read the LCD comments, they can get an alert with the help of this facility. It has 8 channels with each 1.3 minutes recording time. The On-board MIC is used for recording purpose. Supply voltage is $12 \mathrm{v}$ AC/DC. When we switch on the board, LED will be ON. Connect the male to male jumper in the board JP1 section. While in record mode select J5 to select a channel to record the message. Connect M0 to GND. Now record the alert messages. Once the duration has become full the LED will turn off. By this way we can store 8 messages appropriate to the sensors output.

\section{G. Accelerometer Sensor}

An accelerometer sensor will measure the proper acceleration, associated with the weight of a given mass. An accelerometer behaves like a damped mass on a spring. The displacement of accelerometer is measured in order to give the acceleration values. The sensor is attached to the digital (PWM) pins of the Arduino mega. When any one of the axis exceeds the given range of value, the GSM sends alert messages to the registered contact number.

\section{H. Ultrasonic Sensor}

The ultrasonic sensor is used to measure the obstacle in front of the vehicle. The information is displayed in the LCD screen and also a voice message is given. Thus, the speed of the vehicle automatically slows down. The formula to find out the distance is:

Test distance $=$ high level time $\mathrm{x}$ velocity of sound $(340 \mathrm{M} / \mathrm{S})$ / 2

\section{SIMULATION SETUP}

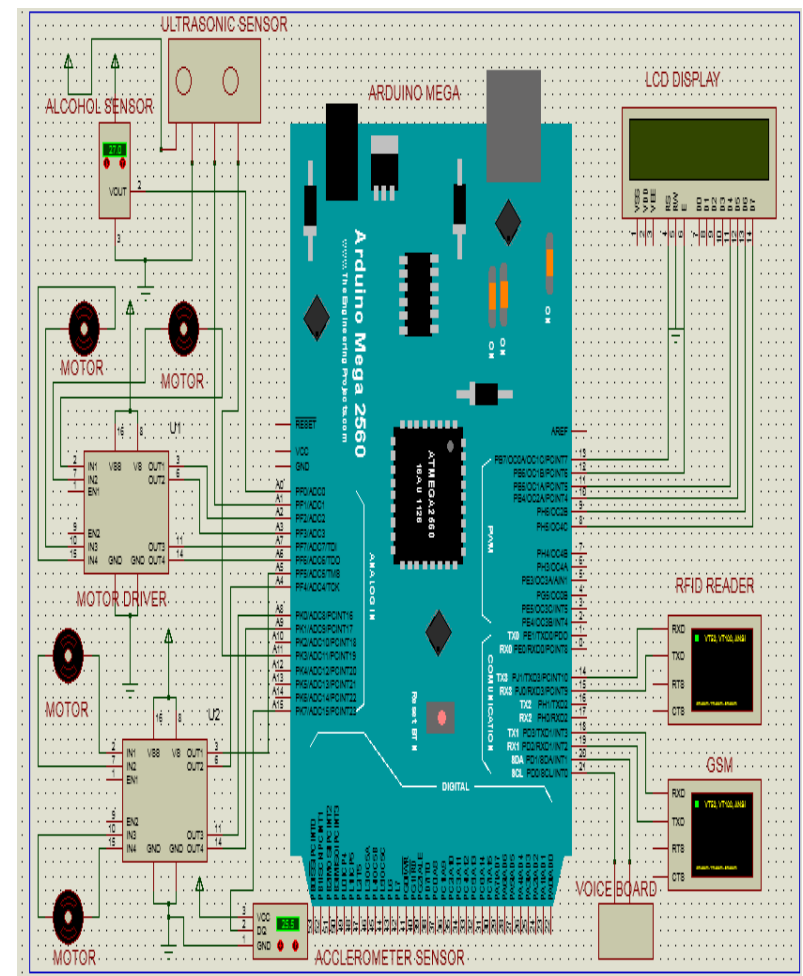

FIG.6

\section{RESULTS}

The proposed system is efficient and the results were obtained. Thus we conclude that the system is very helpful to reduce clashes in the traffic areas.

\section{CONCLUSION}

Hereby, we conclude that the proposed system is verified with suitable results and can be implemented in the vehicles. As the traffic scenario nowadays is very bad, the proposed system would be helpful to the driver. The ultrasonic sensor when detects an obstacle, result is displayed as "GO SLOW". The accelerometer sensor activates when there is an accident and sends a "EMERGENCY" message through GSM. When the RFID reader passes through a tag, it displays "SCHOOL ZONE" message. Thus it intimates the driver about the obstacles and to drive safe in all possible ways.

\section{REFERENCES}

1. Soundararajan R., Ramesh A., Mohanraj N., Parthasarathi N. "An investigation of material removal rate and surface roughness of squeeze casted A413 alloy on WEDM by multi response optimization using RSM." Journal of Alloys and Compounds Volume 685, Year 2016.

2. Gianmarco Baldini , Raimondo Giuliani, Franc Dimc "Road Safety Features Identification Using the Inertial Measurement Unit", , IEEE Sensors Letters Volume: 2 , Issue: 4 , Dec. 2018.

3. Roland Hostettler, Petar M. Djurić "Vehicle Tracking Based on Fusion of Magnetometer and Accelerometer Sensor Measurements With Particle Filtering", , IEEE Transactions on Vehicular Technology Volume: 64 , Issue: 11, Nov. 2015.

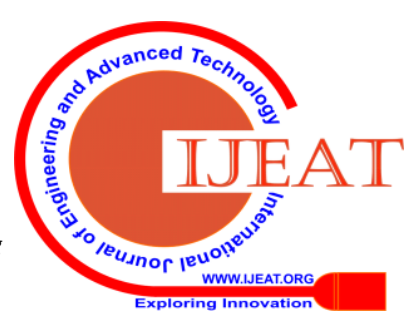


4. Ralf Wunderlich ; Stefan J. Heinen Javier Rivas Road Vibrations as a Source to Detect the Presence and Speed of Vehicles IEEE Sensors Journal Volume: 17, Issue: 2 , Jan.15, 152017.

5. Vivek Agarwal; N. Venkata Murali; C. Chandramouli A Cost-Effective Ultrasonic Sensor-Based Driver-Assistance System for Congested Traffic Conditions IEEE Transactions on Intelligent Transportation Systems Volume: 10, Issue: 3 , Sept. 2009.

6. Prabu Krishnan Design of Collision Detection System for Smart Car Using Li-Fi and Ultrasonic Sensor IEEE Transactions on Vehicular Technology Volume: 67, Issue: 12 , Dec. 2018.

7. Tao Jing ; Xing Wei ; Wei Cheng ; Mingyang Guan ; Liran Ma ; Yan Huo ; Xiuzhen Cheng An Efficient Scheme for Tag Information Update in RFID Systems on Roads IEEE Transactions on Vehicular Technology Volume: 65, Issue: 4 , April 2016

8. Selvy P.T., Palanisamy V., Purusothaman T. "Performance analysis of clustering algorithms in brain tumor detection of MR images" European Journal of Scientific Research Volume 62, Issue 3, Year 2011.

9. Ravindran R., Manonmani K., Narayanasamy R. “ An analysis of void coalescence in AL 5052 alloy sheets annealed at different temperatures formed under different stress conditions." Materials Science and Engineering A Volume 507, Issue 2, Year 2009.

10. Sivaram Kumar V., Thansekhar M.R., Saravanan R., Miruna Joe Amali S. "Solving multi-objective vehicle routing problem with time windows by FAGA" Procedia Engineering Volume 97, Year 2014.

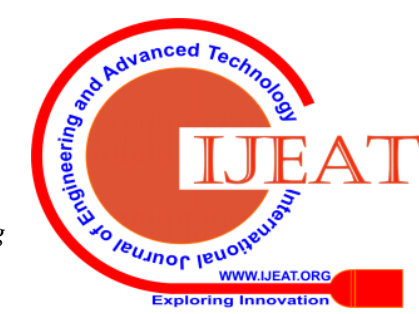

